\title{
Song parameters, repertoire size, and song sharing within and across age classes in the saffron finch
}

María Juliana Benítez Saldívar ${ }^{1,2}$, Carolina Isabel Miño ${ }^{3}$ and Viviana Massoni ${ }^{1}$

${ }^{1}$ Instituto de Ecología, Genética y Evolución - IEGEBA. Universidad de Buenos Aires UBA / Consejo Nacional de Investigaciones Científicas y Técnicas - CONICET. Ciudad Autónoma de Buenos Aires, Argentina

${ }^{2}$ Present Address: Instituto Multidisciplinario de Biología Vegetal, Universidad Nacional de Córdoba, CONICET, FCEFyN, Córdoba, Argentina

${ }^{3}$ Instituto de Biología Subtropical - IBS, Universidad Nacional de Misiones / Consejo Nacional de Investigaciones Científicas y Técnicas - CONICET. Facultad de Ciencias Exactas, Químicas y Naturales, Félix de Azara 1552, Piso 6, N3300LQH. Posadas, Misiones, Argentina

${ }^{\dagger}$ All authors contributed equally to the article.

Corresponding author: Viviana Massoni, Intendente Güiraldes 2160, Ciudad Universitaria - C1428EGA- Buenos Aires, Argentina. E-mail: massoni@ege.fcen.uba.ar

Decision date: $25-$ Oct-2020

This article has been accepted for publication and undergone full peer review but has not been through the copyediting, typesetting, pagination and proofreading process, which may lead to differences between this version and the Version of Record. Please cite this article as doi: [10.1111/jav.02569]. 


\section{ABSTRACT}

Birds sing mostly to attract partners or to defend territories or resources. In relation to the first function, song can vary with age if older experienced males signal their quality through their vocal output. Regarding the second function, song can also vary with age if singing behavior helps mediate social interactions through repertoire sharing with neighbors. Here, we investigate whether song parameters change with age, and in which direction, in saffron finches Sicalis flaveola pelzelni, obligate secondary cavity nesters which produce elaborate melodious songs and show delayed plumage maturation. Cross-sectional comparisons revealed that second year (SY) males sing shorter syllables, and shorter and less versatile songs than older after second year males (ASY), as expected if the latter are more experienced singers. Longitudinal comparisons, which better depict age-related changes, showed that as birds age one year, song length and repertoire size do not change significantly, syllable duration shortens and, as expected for experienced singers, song versatility increases. Correlations between repertoire distance and nesting distance suggest that both SY and ASY males might be adjusting their repertoires to those of ASY neighbors; the former pattern conforms to the expectations if young birds try to emulate the songs of more experienced birds, while the latter is expected if song sharing helps de-escalating antagonistic social interactions amongst males. This research, which provides the first description of song parameters in young second year saffron finches, expands our knowledge of song variation across age classes in songbirds.

Keywords: age-related song variation, cross-sectional comparisons, longitudinal analyses, Neotropical finch, songbird, Thraupidae. 


\section{INTRODUCTION}

For decades, birdsong has long attracted great interest from researchers. From a functional point of view, birdsong has likely evolved as a signal to communicate identity, condition, territorial ownership, reproductive aptitude, or a combination of these (Catchpole and Slater 2008). Variation in birdsong occurs at multiple scales: between species (Robinson and Creanza 2019), among individuals of the same species, and within individuals across their lifetime (Kipper and Kiefer 2010). Birdsong variation has been a target of active research (Podos and Warren 2007, Kiefer et al. 2009), and studies have mostly focused on the meaning of this signal to conspecifics, particularly in the context of sexual selection, in relation to male-male competition and mate choice (Beecher and Brenowitz 2005, Catchpole and Slater 2008, Mason et al. 2016). As singing involves great neurological and muscular effort from singers (Suthers 2004), vocal output is deemed as a reliable indicator of the physical aspects of birds' quality (Suthers 2004). Individuals with certain singing abilities relative to others may have greater reproductive success, achieved either by attracting mates or by deterring sexual competitors (Collins 2004). Variation in song can also be related to social interactions other than mating such as, for example, resource or territory defense (review in Catchpole and Slater 2008). In this context, it has been proposed that, after they have established territory boundaries, individuals or pairs can recognize familiar songs from neighbors and would respond less aggressively to them (Akçay et al. 2010, Searcy et al. 2014); thus, repertoire changes towards achieving more similar songs to those of rivals may help mediate social interactions between males (Beecher 2017).

Many studies suggest that variation in song characteristics is not only related to individual fitness of singers but also to their age (Kipper and Kiefer 2010, Nemeth et al. 2012, Savi 2019). For example, spectrotemporal variables could undergo ontogenetic 
changes at different ages (e.g., de Kort et al. 2009). Frequency bandwith (Veherenkamp et al. 2013, Ota and Soma 2014), peak frequency, song length (Ota and Soma 2014) and trill length (Dalziell and Cockburn 2008) have all been found to increase with the age of singers. In addition, several studies have found that older males sing larger repertoires than young birds (e.g, Vaytina and Shikitov 2019), and that older males are more likely to preferentially use shared songs than younger males (Hyman et al. 2004, Lapierre et al. 2011). Thus, repertoire changes towards achieving more similar songs to those of rivals may help mediate social interactions between males (Beecher 2017).

Songbirds also vary in the time-frame of song acquisition: close-ended learner species memorize their song only during the first year of life and do not change it afterwards, while open-ended species continue to develop new song patterns beyond the first year of life (Brenowitz et al. 1997). Depending on the pattern of song variation with age, open-ended learners can be further categorized into two classes: those which change their songs after the first breeding season, from the first to the second year of life, but no longer (e.g., willow warblers Phylloscopus trochilus, Gil et al. 2001; common nightingales Luscinia megarhynchos, Kiefer et al. 2009), and those which continue changing their songs throughout life (e.g., European starlings Sturnus vulgaris, Eens et al. 1992). In some species, older males sing larger repertoires than young birds (Gil et al. 2001, Forstmeier et al. 2006), and young birds attempt to shape their songs to better resemble those of older singers (Phan et al. 2006) (but see Kipper and Kiefer 2010 for contrasting examples).

Different song characteristics may convey information about different aspects of the singers; therefore, studies on song variation should examine multiple song parameters (Marler 2004), as well as different temporal scales. In this study, we use the saffron finch, Sicalis flaveola pelzelni Sclater, PL, 1872 as a model to study song variation at 
multiple dimensions. This southern temperate secondary cavity nester produces an elaborate vocal signal, and shows delayed plumage maturation (DPM, age-related plumage coloration differences, Hawkins et al. 2012), a characteristic which enables distinguishing first breeders from older males (Palmerio and Massoni 2009). Secondyear males (hereafter SY males) are dull, of female-like appearance and indistinguishable from females to conspecifics (Benítez Saldívar and Massoni 2018), while after second-year males (hereafter ASY males) are overall golden yellow. Species that show DPM could also show age-related vocal maturation (Cucco and Malacarne 2000), and several studies have confirmed such an association (Kipper and Kiefer 2010, Poesel and Nelson 2012, Vabischevich 2012). In a previous study, we described the spectrotemporal variables and the vocal repertoires of saffron finch ASY males during one breeding season $(n=14)$ and found a large mean syllable repertoire size $(25$ syllables), with different syllables freely recombined in many different sequences, such that song repertoire size never reaches a plateau (see Fig. 4 in Benítez Saldívar and Massoni 2017).

Here, building upon our previous study, we describe, for the first time, the spectrotemporal variables, syllable repertoire size, and versatility in saffron finches SY males, and investigate whether those variables change, and in which direction, in relation to age, by comparing SY, ASY, and older ASY males. We use both crosssectional analyses (i.e., comparison of groups of individuals across age classes, Kipper and Kiefer 2010, Osiejuk et al. 2019) as well as longitudinal analyses of marked individuals across different ages (Forstmeier et al. 2006). We also investigate spatial patterns of syllable sharing in the repertoires of SY and ASY males breeding at the same site. If, like other songbirds, older saffron finch males are more experienced singers, we expect young males to show smaller values of frequency and shorter values 
of temporal variables, less versatile songs, and smaller repertoire sizes. In addition, assuming that syllable sharing helps de-escalating agonistic interactions between males, we expect that repertoire similarity would be greater among neighbors than among distant males. Finally, if young saffron finches attempt to shape their songs to resemble those produced by older males (instead of those produced by young neighbors), we expect that repertoire similarity amongst neighboring ASY males would be greater than those observed amongst neighbors SY males. Contrary to our expectations, we found that most frequency variables and repertoire size do not seem to be affected by age, while temporal variables do. In agreement with our expectations, we found less versatile songs in young males, greater repertoire similarity among neighbors than among distant males, and greater repertoire similarity amongst older males than amongst younger saffron finches.

\section{METHODS}

\section{Study site and species}

Our study-system is composed of 126 nest-boxes mounted on fence posts delimiting agricultural paddocks surrounding the Instituto de Investigaciones Tecnológicas de Chascomús (INTECH-CONICET), situated in lowland pampas habitat in Buenos Aires Province, Argentina (35 34'S, $\left.5801^{\prime} \mathrm{W}\right)$. We captured and banded all breeding adults when they entered the nest-boxes (for details, see Palmerio and Massoni 2009). Birds were banded with a numbered aluminum ring and three plastic color bands for individual identification. Females were identified by the presence of a brood patch; males were identified based on singing behavior (only males sing in this subspecies), or by the presence of a cloacal protuberance: ASY males were further distinguished based on their bright-yellow plumage (Benítez Saldívar and Massoni 2018). From previous 
studies, we know that SY males sing and reproduce successfully in the vicinity of ASY males (Palmerio and Massoni 2009, 2011), and that ASY males have a mean syllable repertoire size of $25 \pm 1.9$ syllables (Benítez Saldívar and Massoni 2017); however, syllable repertoire or other variables of SY males vocal output have not been yet characterized. Here, we analyzed 39 males, seven of which ASY males were described in Benítez Saldívar and Massoni (2017); for these, we added 96 extra songs (an average of 32 new recordings per male). We expand the time-frame studied to two breeding seasons, and describe the vocal signal of SY males for the first time.

\section{Recording and characterization of vocal output}

Saffron finches were recorded during two consecutive breeding seasons (October to March 2014-2015 and 2015-2016). Spontaneously singing males were recorded during the hours of greatest activity (from 5:00 AM to 13:00 PM, and from 16:00 to 19:00 PM), from a distance of 20-30 m, while perched near nest-boxes or on a neighboring tree (Benítez Saldívar and Massoni 2017). As saffron finches are multi-brooded (Palmerio and Massoni 2009, 2011), and continue to sing after they have mated for the first time, males were recorded throughout the breeding season. We used a Marantz PMD 661 Professional Solid State Recorder and a Sennheiser ME66+K6 shotgun microphone. The recordings were made at a sampling rate of $44.1 \mathrm{kHz}$ and 16-bit depth and stored as uncompressed WAV files. Spectrograms were visualized in RavenPro 1.4 software (Cornell Lab of Ornithology, Ithaca, NY, USA) using the Hann spectrogram window type with 256 samples, a discrete Fourier transform (DFT) size of 256 samples and a grid spacing of $2.9 \mathrm{~ms}$, with a temporal overlap of $50 \%$. As in Benítez Saldívar and Massoni (2017), notes were defined as continuous traces in a spectrogram, and syllables were defined as a single note or a set of notes that are typically grouped together. As in Benítez Saldívar and Massoni (2017), syllable classification was 
performed by visual inspection of spectrograms; two syllables were considered as belonging to the same type when they shared fine-grained consistency in shape, duration and bandwidth. Given that song repertoire size never reaches a plateau in this subspecies (Fig. S1 and see Fig. 4 in Benítez Saldívar and Massoni 2017), therefore, as Slater and Gil (2000) propose, is not adequate to use the song type concept. Hence, from now on, we use the term song to refer to a sequence of syllables arranged over a short-time interval separated from the following song for a silent interval of over $1 \mathrm{~s}$ (Sosa-López and Mennill 2014). For the spectrograms of each bird in each season, we measured, by hand with on-screen cursor, the following acoustic parameters: maximum frequency (the frequency of the highest syllable in the song, $\mathrm{kHz}$ ), minimum frequency (the frequency of the lowest syllable in the song, $\mathrm{kHz}$ ), frequency bandwidth (difference between the maximum and the minimum syllable frequencies in the song, $\mathrm{kHz}$ ), peak frequency (frequency of maximum power of the song, $\mathrm{kHz}$ ), song length (duration of a song from the beginning of the first syllable to the end of the last syllable, sec) and syllable duration (the mean syllable duration per song and male, sec). We computed the syllable rate (the number of syllables produced per second, song and male, as in Geberzahn and Aubin 2014), the Song Versatility Index (the ratio between different syllables and the total number of syllables per song and male, Slater and Gil 2000) and the Syllable Repertoire Size (the number of different syllables produced by a given male, once the cumulative number of syllables reached an asymptote with increasing number of songs analyzed; see Benítez Saldívar and Massoni 2017 for further details on this index).

\section{Statistical analyses}

Using cross-sectional analyses, we compared the above mentioned spectrotemporal variables and indexes between SY $(n=22)$ and ASY males $(n=17)$. The group of 
ASY males includes individuals that were banded as SY and are, therefore, of known age, as well as males that were banded as ASY, and are of unknown age. To avoid pseudo-replication, we used, for each male, data from a single breeding season. We computed the Repertoire Similarity Index, i.e., a pairwise comparison of the syllable repertoire of two males, using the formula: 2 Ns / (R1+R2), where Ns is the number of syllables shared; R1 is the repertoire size of male 1 and $\mathrm{R} 2$ is the repertoire size of male 2 (McGregor and Krebs 1982).

We conducted longitudinal analyses to compare the above mentioned spectrotemporal variables and indexes between SY males $(n=8)$ and the same males becoming ASY in the next year, and between ASY males $(n=8)$ of unknown age and the same males becoming ASY+1 males in the second year recorded. For these two age classes, we also adjusted the formula of the Repertoire Similarity Index described above to focus on the proportion of syllables sung by the same males in two seasons, such that R 1 is the repertoire size of a male in the first season, and R2 that of the same male in the second season recorded (Mamede and Mota 2012). We computed repertoire similarity separately for both age groups because one includes males of known age (SY becoming ASY), and the other includes males of unknown age (ASY-ASY+1).

All of the cross-sectional and longitudinal comparisons described above were made using two-sample Student's $t$-tests or Wilcoxon Rank Sum tests when data did not distribute normally. To evaluate the magnitude of the differences between age classes, we computed Cohen's d measure of effect sizes for the cross-sectional analysis and Hedges' g correction for small sample sizes $(\mathrm{n}<20)$ for the longitudinal analyses, using the 'cohen_d()' function in the 'rstatix' package (Kassambara 2020) in R statistical environment (R Core Team 2019). Following Nakagawa and Cuthill (2007, p. 603), we interpreted the results of the cross-sectional and longitudinal analyses using the dual 
approach which considers the point estimates of the effects of interest, as well as their precision (confidence intervals).

To evaluate the degree of syllable sharing amongst reproductive males at the study site, we tested the association between the geographic proximity of males, and their syllable repertoire distance (Demko et al. 2016). We used the linear distance between nest-boxes (m), as a measure of distance between males, and built a matrix of distances using Geographic Distance Matrix Generator (Ersts 2011), based on the geographical position of each nest-box recorded with a Garmin Etrex GPS (precision $\pm 3 \mathrm{~m}$ ). As a measure of repertoire distance, we used the syllable repertoire dissimilarity, 1-RS (Vargas-Castro 2015, Demko 2016), and built a matrix of this index between pairs of males. To account for the possible influence of plumage coloration (proxy of age) on the association between geographic distance and repertoire similarity, we carried out Partial Mantel test separately for each breeding season. The 'color' matrix was built by coding 0 for pairs of same-colored SY males, 1 for same-colored ASY males, and 2 for pairs of dissimilar color (following Forstmeier et al. 2006). All of these tests were carried using the 'partial.mantel' function implemented in the 'vegan' package, setting 10000 iterations (Oksanen et al. 2017) in R.

\section{RESULTS}

\section{Cross-sectional analyses between SY and ASY males}

We recorded a total of 39 males (26 males in 2014, and 29 males in 2015) and analyzed a total of 4226 songs, with $108.35 \pm 7.40($ mean $\pm \mathrm{SE})$ songs per male $\left(\mathrm{n}_{\mathrm{SY}}=22, \mathrm{n}_{\mathrm{ASY}}\right.$ =17). Results of cross-sectional analyses, effect sizes and respective confidence intervals are given in Table 1. Minimum frequency, bandwidth, song length and syllable duration had small effect sizes; the latter two variables could be estimated with a small 
95\% CIs (Table 1). Maximum frequency and syllable rate had medium effect sizes, while peak frequency and repertoire size had large effect sizes, but all of these variables could be estimated with large 95\% CIs (Table 1).

\section{Longitudinal analysis of SY males that became ASY males}

Sixteen males were recorded in two seasons: eight SY males that returned as ASY males in the following season, and eight ASY males in two consecutive breeding seasons. We recorded 1,080 songs from 8 SY males and 956 songs from the same individuals in the following year as ASY males. We analyzed $134.9 \pm 22.9$ songs per male in the 2014-2015 season and $118.1 \pm 15.6$ songs in 2015-2016. Results of longitudinal analysis, effect sizes and their 95\% CI are shown Table 2. Maximum frequency, bandwidth, song length, syllable rate and repertoire size had small effect sizes; minimum frequency and peak frequency had medium effect sizes, syllable duration and Song Versatility Index had large effect sizes, all of these could be estimated with large 95\% CIs (Table 2). Syllable repertoire size increased in five males but decreased in the rest, as can be seen Fig. 1a. After-second-year males retained an average of 59\% syllables from the previous year, dropped 22\% syllables, and added 19 $\%$ new syllables. However, these newly recorded syllables have a low percentage of use $(0.1-15.08 \%), 1.96 \pm 0.40 \%$ (mean \pm SE). The Repertoire Similarity Index for these males was $0.74 \pm 0.03$ (range: $0.59-0.81$ ).

\section{Longitudinal analyses of ASY males turning into ASY+1 males}

We recorded 975 songs from ASY males $(n=8)$ and 792 songs from the same individuals as ASY+1 males, with an average of $129.6 \pm 13.6$ (mean \pm SE) songs per male in the first season and 101.6 \pm 11.5 in the second season of recording. Results of longitudinal analysis, effect sizes and their 95\% CI are shown in Table 3. Minimum frequency, song length syllable rate and repertoire size showed small effect sizes; 
maximum frequency, bandwidth, peak frequency and song versatility index showed medium effect sizes; finally, syllable duration showed a large effect size; all of these could be estimated with large $95 \%$ CIs, except song length which could be estimated with a small CI (Table 3). Five out of 7 males slightly changed their repertoire size by one or two syllables, one male increased it and another decreased it in both cases by 12 syllables, resulting in no substantial change in repertoire size between years, as can be seen in Fig.1b. After-second-year males retained an average of $69 \%$ of syllables between years, dropped $16 \%$ of syllables and added $17 \%$ of new syllables as ASY+1 males; the newly recorded syllables were used infrequently $(0.19-9.18 \%) 1.26 \pm 0.28$ $\%$ (mean \pm SE). The Repertoire Similarity Index for these males was $0.81 \pm 0.04$ (range: $0.62-0.97)$

\section{Syllable sharing, nest-box distance and age between males}

Repertoire distance (1-RS) was significantly correlated with distance between nestboxes for all males, both in 2014-2015 (Mantel tests, $r=0.24, \mathrm{p}=0.008$ ) and in 2015$2016(r=0.28, \mathrm{p}=0.002)$; after accounting for age classes, this correlation was still statistically significant for both breeding seasons (Partial Mantel tests: 2014-2015: $r=$ $0.04, p=0.007 ; 2015-2016: r=0.28, p=0.003)$. Repertoire distance (1-RS) of SY males was not significantly correlated with their nest-box distance, either in 2014-2015 (Mantel tests $r=0.03, p=0.40$, Fig.2a) or in 2015-2016 ( $r=-0.05, p=0.55$, Fig. 2b), comparisons between SY and ASY males showed that repertoire distance (1-RS) was significantly correlated with nest-box distance in both seasons analyzed (Mantel tests: 2014-2015: $r=0.78, \mathrm{p}<0.0001 ; 2015-2016: r=0.84, \mathrm{p}<0.0001$, Fig. 2c, 2d). while for ASY males, repertoire distance (1-RS) was significantly correlated with nest-box distance both in 2014-2015 ( $r=0.81, p<0.0001$, Fig. 2 e $)$ and 2015-2016 $(r=0.21, p=$ 0.03, Fig. 2e) breeding seasons. 


\section{DISCUSSION}

We characterize, for the first time, the song of second-year dull males. Most of the saffron finches' frequency variables of song do not change with age, while temporal variables do. We found compelling evidence of the importance of syllable sharing in this species, which we discuss in the context of mediating antagonistic social interactions related to defense of nesting resources.

\section{Song parameters and repertoire size across age classes}

We found that second year saffron finch males have a higher peak frequency (large effect size, large CI), a shorter song length (small effect size, small CI), a shorter syllable duration (small effect size, small CI) and smaller versatility (large effect, large CI) than after second year males (Table 1). Second year males also had larger repertoires (large effect size, large CI) than after second year males (Table 1). Results from longitudinal analyses of second year males turning into after second year males, and of ASY aging one year show that syllable duration decreases with age, versatility increases with age, and both age classes had similar repertoire sizes (small effect)

(Table 2, Table 3). Song length, however, does not seem to change from SY to ASY, but decreases as ASY birds age one year (small effect size, small CI) (Table 2, Table 3). Both the cross-sectional and longitudinal methods show opposite results in the direction of change of song length and syllable duration. Interestingly, both methods are concordant in showing that song versatility increases with age, suggesting that this song parameter may be an important signal of age. Most published studies analyze repertoire size, and show that older males sing larger repertoires than young birds (eg., the willow warbler, Phylloscopus trochilus, Gil et al. 2001, the great reed warbler Acrocephalus arundinaceu, Forstmeier et al. 2006); however, in the present study in saffron finches, 
the cross-sectional analysis shows a reduction in repertoire size, while longitudinal analyses did not detect significant changes. An increased repertoire size in the dull males might be a strategy to make their vocal signal more attractive to females (Lampe and Sætre 1995) and to counteract their age and lack of the definitive plumage. Alternatively, it could be a case of overproduction and selective attrition (Peters and Nowicki 2017); however, in order to entertain this hypothesis, we should record and characterize the repertoire size of individuals at their natal grounds, which is likely unattainable in this species as only $0.05 \%$ of second year males show natal site fidelity (pers. obs.).

Cross-sectional comparisons have the advantage of larger sample sizes, but longitudinal analyses which follow focal individuals through time are more powerful than the former in depicting age-related changes in birdsong (Balsby and Hansen 2010). Despite the fact that we used analytical procedures specifically designed to account for low sample sizes, this potential limitation of our longitudinal analyses prevent us for drawing further conclusions. It is worth noting here that in species with large repertoires (Botero et al. 2008), such as the saffron finch, longitudinal studies are highly demanding, mostly due to the difficulty of recording a comparable number of vocalizations of the same individual in consecutive seasons (Kipper and Kiefer 2010).

The results of our longitudinal analyses indicate that saffron finches do change the composition of their repertoires after the first year and later in life, suggesting that this species may be an open-ended learner, in line with what has been proposed in other songbirds based on evidence of similar nature (Robinson et al. 2019). Changes in song parameters in saffron finches seem to continue after the second breeding season, in contrast to what happens in other open-ended learners, in which changes occur mostly after the first breeding season (Kipper and Kiefer 2010). 
Interestingly, despite that newly recorded syllables have a low frequency of use in both age classes, results of longitudinal analyses showed an important syllable turnover between second-year males and ASY males, and also in ASY males they age one year. Understanding the origin of the repertoire of syllables underlining the turnover observed in saffron finches breeding at our study site is difficult. One possibility is that birds sing syllables previously acquired at their hatching grounds, which remained "silent" in their first breeding seasons (Geberzahn and Hultsch 2003). Alternatively, they may be truly learning new syllables every season. The average recruitment rate of nestlings banded at the study site in this species is very low $(0.05 \%)$, and the breeding site fidelity between years ranges from $36 \%$ in second-year males to $51 \%$ in after-second year males (pers. obs.). These return rates indicate that almost $70 \%$ of SY males and half of ASY males arrive from different hatching or breeding areas, likely bringing along song elements different from those sung at our study site. These large percentages suggest that the first possibility is more likely to occur, but this cannot be fully distinguished in this study. Nonetheless, the two explanations are not mutually exclusive. Future research in saffron finches should focus on conducting controlled longitudinal laboratory experiments to describe what syllables each focal individual hear, and which syllables they sing in successive years (Hesler et al. 2012), as a means of elucidating the mechanisms of song learning.

\section{Song sharing and nest-box distance}

Saffron finch males, show delayed plumage maturation, with SY males resembling females (Benítez Saldívar and Massoni 2018), and disclose their presence at the breeding ground through overt singing. As a means of inspecting age-related patterns of song sharing amongst saffron finches, we investigated the relationship between nest-box distance and similarity of songs' repertoire size. Comparing all the males breeding at 
our study site, we found that distance between next-boxes was related to repertoire similarity, indicating that nearby nesting males sing more similar songs than more distant males. This relationship holds when accounting for age. Looking more deeply into this pattern of age-related differences in repertoire similarity and nesting distance, our results suggest that SY males may not adjust their songs to those of other young neighbors (Fig. 2a, 2b), which produce shorter syllables and less versatile songs (Table 1); in line with this, our results also suggest that SY males might be adjusting their repertoires to those of ASY neighbors (Fig. 2c, 2d), which have a longer syllable duration and produce more versatile songs (Table 1); finally, our results suggest that older ASY males could be adjusting their syllable repertoires to those of ASY neighbors (Fig. 2e, 2f). This relationship between repertoire similarity and nesting distance is less steep in the second breeding season (2015-2016) than in the first (2014-2015) (Fig. 2e, 2f). This pattern could be explained if we take into account the fact that, in the second breeding season recorded, ASY males nested more dispersed in the study-site, while in 2014-2015 they nested in a more clustered pattern (Fig. S2a, S2b). A complementary explanation to this pattern could be that most ASY males in the second breeding season recorded were unfamiliar to each other's repertoires. This is because, with a similar sampling effort in both breeding seasons, we recorded the great majority of nesting ASY males; we know that only $38 \%$ of the ASY males recorded during the second breeding season (2015-2016) were retuning males, as they had been recorded in the first season as SY males. Therefore, most of the ASY males breeding in 2015-2016 shared a lower proportion of their syllable repertoires than ASY males in the first breeding season (2014-2015).

Shared songs are a reliable signal of familiarity or locality since they must be learned in the breeding neighborhood (Beecher 2017). The patterns of repertoire similarity 
observed in saffron finches ASY males could be explained if in this species song (or syllable) sharing also plays a key role in de-escalating antagonistic social interactions amongst males, as proposed for other species (Akçay et al. 2010, Searcy et al. 2014, Beecher 2017). Aggressive social conflicts amongst males are not uncommon in saffron finches, which, as do other obligate secondary cavity nesters (Brazill-Boast et al. 2011, Cantarero et al. 2015), fiercely defend their nesting cavities - often limiting crucial breeding resources (Wiebe 2011) - from intruders (Benítez Saldívar 2018), particularly from same sex conspecifics (Arhex 2007). Thus, we argue that saffron finch ASY males adjust their songs to be more similar to that of their neighbors as a mean of reducing the magnitude of conspecific aggressions. Interestingly, in spite of SY and ASY males' nests being interspersed, we have only observed intensive and even fatal aggression between ASY males, and never between SY and ASY males (Benítez Saldívar 2018). As dull second-year males show no significant differences with yellow after-second year males in social reproductive success and parental care (Palmerio and Massoni $2009,2011)$, to better understand the social environment in which song similarity is acquired in this species, future studies should investigate if syllable sharing affects nestbox occupancy, mate fidelity, or mating success.

In summary, this study contributes to increase the knowledge of song parameters in saffron finch males breeding at Southern temperate latitudes and provides novel information on song variation across age classes. Results of the cross-sectional and longitudinal analyses agree in showing that frequency variables of song are not affected by age, while temporal variables are. After second year yellow males showed increased repertoire similarity at closer nesting distances, while second year dull males did not, which suggests that patterns of song sharing improve with age in this Neotropical thraupid. 


\section{DECLARATIONS}

Acknowledgements - MJBS wishes to thank L. Galetto and J.I. Areta for early comments of the draft. We thank the authorities and personnel of the Instituto Tecnológico de Chascomús (INTECH-CONICET) for permission to work and reside on its premises. CIM wishes to thank Indio for his love, support, and patience. VM wishes to thank Ricardo A. Russo.

Funding - This work was supported through Research Grants awarded to VM by Consejo Nacional de InvestigacionesCientíficas y Técnicas - CONICET, Argentina (PIP 2014-2017: \#11220130100342CO) and Universidad de Buenos Aires (UBACyT2014-2017: \#20020130100772BA). MJBS acknowledges the Doctoral Scholarship awarded by CONICET (\#4370/2012).

Author contributions - MJBS performed field work, collected data, analyzed the data, interpreted results, and drafted the manuscript; CIM interpreted results, and wrote, revised and edited the manuscript; VM conceptualized the study, interpreted results, wrote, revised and edited the manuscript, and provided funding for field work.

Conflicts of interest - None to declare.

Permit(s) - All methods employed related to capturing, handling, and banding of the birds comply with the guidelines of the Dirección de Flora y Fauna (Buenos Aires province, Argentina. Specific permits to handle the birds were obtained from the Dirección de Flora y Fauna (permits No. 142/2013, 153/2014 and 65/2015). No animals were harmed during capture, and neither anesthesia nor euthanasia was required. The field studies did not involve endangered or protected species. 


\section{REFERENCES}

Akçay Ç., Reed V. A., Campbell S. E., Templeton C. N., and Beecher M. D. (2010). Indirect reciprocity: song sparrows distrust aggressive neighbours based on eavesdropping. An.Behav. 80(6): 1041-1047.

Arhex, M. I. 2007. Respuesta de machos y hembras del Jilguero Dorado (Sicalisflaveola) a la intrusión territorial de conespecíficos.Thesis, Universidad de Buenos Aires, Argentina.

Balsby, T. J. S. and Hansen, P. 2010. Element repertoire: Change and development with age in Whitethroat Sylvia communis song. - J. Ornithol. 151: 469-476.

Beecher, M. D. (2017). Birdsong learning as a social process. Animal Behaviour, 124, 233-246.

Beecher, M. D. and Brenowitz, E. A. 2005. Functional aspects of song learning in songbirds. - Trends Ecol. Evol. 20: 143-149.

Beecher, M. D., Campbell, S. E. and Nordby, J. C. 2000. Territory tenure in Song Sparrows is related to song sharing with neighbours, but not to repertoire size. - Anim. Behav. 59: 29-37.

Benítez Saldívar, M. J. and Massoni, V. 2017. Song structure and syllable and song repertoires of the Saffron Finch (Sicalisflaveola pelzelni) breeding in Argentinean pampas. - Bioacoustics 4622: 1-14.

Benítez Saldívar, M. J. 2018. Maduración tardía del plumaje, comunicación visual y acústica en el Jilguero Dorado Sicalisflaveola pelzelni: su efecto en el éxito reproductivo y la elección de pareja social y genética. PhD Thesis, Univ. de Buenos Aires, Argentina. 
Benítez Saldívar, M. J. and Massoni, V. 2018. Lack of conspecific visual discrimination between second-year males and females in the Saffron Finch. - PLoS One 13: 1-16.

Botero, C. A., Mudgeb, A. E., Koltzd, A. M., Hochachkab, W. M. and Vehrencamp, S.

L. 2008. How reliable are the methods for estimating repertoire size? - Ethology 114: $1227-1238$.

Brazill-Boast, J., Van Rooij, E., Pryke, S. R. and Griffith, S. C. 2011. Interference from long-tailed finches constrains reproduction in the endangered Gouldian Finch. - J. Anim. Ecol. 80: 39-48.

Brenowitz, E. A., Margoliash, D., and Nordeen, K. W. 1997. An introduction to birdsong and the avian song system. J. Neurobiol33: 495-500.

Cantarero, A., Laaksonen, T., Jarvisto, P. E., Gil, D., López-Arrabe, J., Redondo, A. J. and Moreno, J. 2015. Nest DefenceBehaviour and Testosterone Levels in Female Pied Flycatchers. - Ethology 121: 946-957.

Catchpole, C. and Slater, P. 2008. Bird song, biological themes and variations. Cambridge University Press.

Center for Conservation Bioacoustics. 2011. Raven Pro: Interactive Sound Analysis Software (Version 1.4) [Computer software]. Ithaca, NY: The Cornell Lab of Ornithology. Available from http://ravensoundsoftware.com/

Collins, S. 2004. Vocal fighting and flirting: the functions of birdsong. In: Marler, P. and Slabbekoorn, H. 2004. Nature's music - The science of birdsong (pp. 39-79). Academic Press.

Cucco, M. and Malacarne, G. 2000. Delayed maturation in passerine birds: an examination of plumage effects and some indications of a related effect in song. - Ethol. Ecol. Evol. 12: 291-308. 
Demko, A. D., Reitsma, L. R. and Staicer, C. A. 2016. Repertoire structure, song sharing, reproductive success, and territory tenure in a population of Canada Warblers (Cardellina canadensis) in central New Hampshire. - Can. J. Zool 290: 283-290.

Eens, M., Pinxten, R. and Verheyen, R. F. 1992. Song learning in captive European Starlings, Sturnus vulgaris. - Anim. Behav. 44: 1131-1143.

Ersts, P. 2011. Geographic Distance Matrix Generator. (version 1.2.3). American Museum of Natural History, Center for Biodiversity and Conservation.

Forstmeier, W., Hasselquist, D., Bensch, S. and Leisler, B. 2006. Does song reflect age and viability? A comparison between two populations of the great reed warbler Acrocephalus arundinaceus. - Behav. Ecol. Sociobiol. 59: 634-643.

Garamszegi, L. Z., Balsby, T. J. S., Bell, B. D., Borowiec, M., Byers, B. E., Draganoiu, T., Eens, M., Forstmeier, W., Galeotti, P., Gil, D., Gorissen, L., Hansen, P., Lampe, H. M., Leitner, S., Lontkowski, J., Nagle, L., Nemeth, E., Pinxten, R., Rossi, J. M., Saino, N., Tanvez, A., Titus, R., Török, J., Van Duyse, E. and Møller, A. P. 2005. Estimating the complexity of bird song by using capture-recapture approaches from community ecology. - Behav. Ecol. Sociobiol. 57: 305-317.

Garamszegi, L. Z., Torok, J., Hegyi, G., Szollosi, E., Rosivall, B. and Eens, M. 2007. Age-dependent expression of song in the Collared Flycatcher, Ficedula albicollis. Ethology 113: 246-256.

Geberzahn, N. and Hultsch, H. 2003. Long-time storage of song types in birds: evidence from interactive playbacks. - Proc. R. Soc. B Biol. Sci. 270: 1085-90.

Gil, D., Cobb, J. L. S. and Slater, P. J. B. 2001. Song characteristics are age dependent in the Willow Warbler, Phylloscopustrochilus. - Anim. Behav. 62: 689-694. 
Gill, S. A., Costa, L. M. and Hau, M. 2008. Males of a single-brooded tropical bird species do not show increases in testosterone during social challenges. - Horm. Behav. 54: $115-124$.

Hesler, N., Mundry, R. and Dabelsteen, T. 2012. Are there age-related differences in the song repertoire size of Eurasian blackbirds? - Acta Ethol. 15: 203-210.

Hyman J, Hughes M, Searcy WA, Nowicki S (2004) Individual variation in the strength of territory defense in song sparrows: correlates of age, territory tenure, and neighbour aggressiveness. Behaviour 141:15-27

Kiefer, S., Sommer, C., Scharff, C., Kipper, S. and Mundry, R. 2009. Tuning towards tomorrow? Common Nightingales Lusciniamegarhynchos change and increase their song repertoires from the first to the second breeding season. - J. Avian Biol. 40: 231236.

Kipper, S. and Kiefer, S. 2010. Age-Related Changes in Birds' Singing Styles. - Adv. Study Behav. 41: 77-118.

Lampe, H. M. and Sætre, G.-P. 1995. Female Pied Flycatchers Prefer Males with Larger Song Repertoires. - Proc. R. Soc. B 262: 163-167.

Lapierre JM, Mennill DJ, MacDougall-Shackleton EA. 2011. Spatial and age-related variation in use of locally common song elements in dawn singing of song sparrows Melospiza melodia: old males sing the hits. -Behav. Ecol. Sociobiol. 65: 2149-2160. Mamede, A. T. and Mota, P. G. 2012. Limited Inter-Annual Song Variation in the Serin (Serinus serinus). - Ethology 118: 1157-1164.

Marler, P. 2004. Science and birdsong: the good old days. - In: Nature's music: The science of birdsong. pp. 1-37. Academic Press. 
Mason, N. A., Burns, K. J., Tobias, J. A., Claramunt, S., Seddon, N. and Derryberry, E. P. 2016. Song evolution, speciation, and vocal learning in passerine birds. - Evolution 71: 786-796.

McGregor, P. K. and Krebs, J. R. 1982. Song types in a population of Great Tits (Parus major): their distribution, abundance and acquisition by individuals. - Behaviour 79: $126-152$.

Nakagawa, S. and Cuthill, I. C. 2007. Effect size, confidence interval and statistical significance: a practical guide for biologists. - Biol. Rev. Camb. Philos. Soc. 82: 591605.

Oksanen, J., Blanchet, F. G., Friendly, M., Kindt, R., Legendre, P., McGlinn, D., Minchin, P. R., O’Hara, R. B., Simpson, G. L., Solymos, P., Henry, M., Stevens, H., Szoecs, E., and Wagner, H. 2017. vegan: Community Ecology Package. R package Version 2.4-3. https://CRAN.R-project.org/package=vegan.

Osiejuk, T. S., Losak, K., Steifetten, O. and Dale, S. 2019. Songbird presumed to be age-limited learner may change repertoire size and composition throughout their life. J. Zool. 309: 1-10.

Palmerio, A. G. and Massoni, V. 2009. Reproductive Biology of female Saffron Finches does not differ by the plumage of the mate. - Condor 111: 715-721.

Palmerio, A. and Massoni, V. 2011. Parental care does not vary with age-dependent plumage in male Saffron Finches Sicalisflaveola. - Ibis 153: 421-424.

Peters, S. and Nowicki, S. 2017. Overproduction and attrition: the fates of songs memorized during song learning in songbirds. - Anim. Behav. 124: 255-261. 
Phan, M. L., Pytte, C. L. and Vicario, D. S. 2006. Early auditory experience generates long-lasting memories that may subserve vocal learning in songbirds. - Proc. Natl. Acad. Sci. 103: 1088-1093.

Podos, J. and Warren, P. S. 2007. The Evolution of Geographic Variation in Birdsong. Adv. Study Behav. 37: 403-458.

Poesel, A. and Nelson, D. A. 2012. Delayed song maturation and territorial aggression in a songbird. - Biol. Lett. 8: 369-371.

R Core Team (2019). R: A language and environment for statistical computing. R Foundation for Statistical Computing, Vienna, Austria. URL https://www.Rproject.org/.

Robinson, C. M., Snyder, K. T. and Creanza, N. 2019. Correlated evolution between repertoire size and song plasticity predicts that sexual selection on song promotes openended learning. - Elife 8: 1-26.

Searcy, W. A., Akçay, C., Nowicki, S. and Beecher, M. D. 2014. Aggressive Signaling in Song Sparrows and Other Songbirds. - Adv. Study Behav. 46: 89-125.

Slater, P. J., and Gil, D. 2000. Song organisation and singing patterns of the willow warbler, Phylloscopus trochilus. - Behav. 137: 759-782.

Sosa-López, J. R. and Mennill, D. J. 2014. The vocal behavior of the Brown-throated Wren (Troglodytes brunneicollis): Song structure, repertoires, sharing, syntax, and diel variation. - J. Ornithol. 155: 435-446.

Suthers, R. A. 2004. How birds sing and why it matters. Nature's music: the science of birdsong. Elsevier Academic Press, San Diego, 272-295. 
Vabishchevich, A. P. 2012. Two Strategies of between-Season Changes in the Song

Composition of the Pied Flycatcher. - Ann. Zool. Fennici 49: 219-230.

Vargas-Castro, L. E. 2015. Spatial pattern of syllable sharing in White-throated

Thrushes: implications for song learning and dispersal behaviours. - Behaviour 152: $775-795$.

Vaytina, T. M., and Shitikov, D. A. 2019. Age-related changes in song repertoire size and song type sharing in the Whinchat Saxicola rubetra. - Bioacoustics 28: 140-154.

Wiebe, K. L. 2011. Nest sites as limiting resources for cavity-nesting birds in mature forest ecosystems: a review of the evidence. - J Field Ornithol. 82: 239-248. 


\section{FIGURE LEGENDS}

Figure 1. Variation in syllable repertoire size with age in saffron finches breeding in Chascomús. Buenos Aires. Argentina. a) Comparison between birds recorded in 20142015 as second-year males (grey bird silhouette) versus the same males recorded in 2015-2016 as after second-year males (yellow bird silhouette); b) Comparison between birds recorded in 2014-2015 as after second-year males versus the same males recorded in 2015-2016. Dashed lines of different colors indicate different birds.
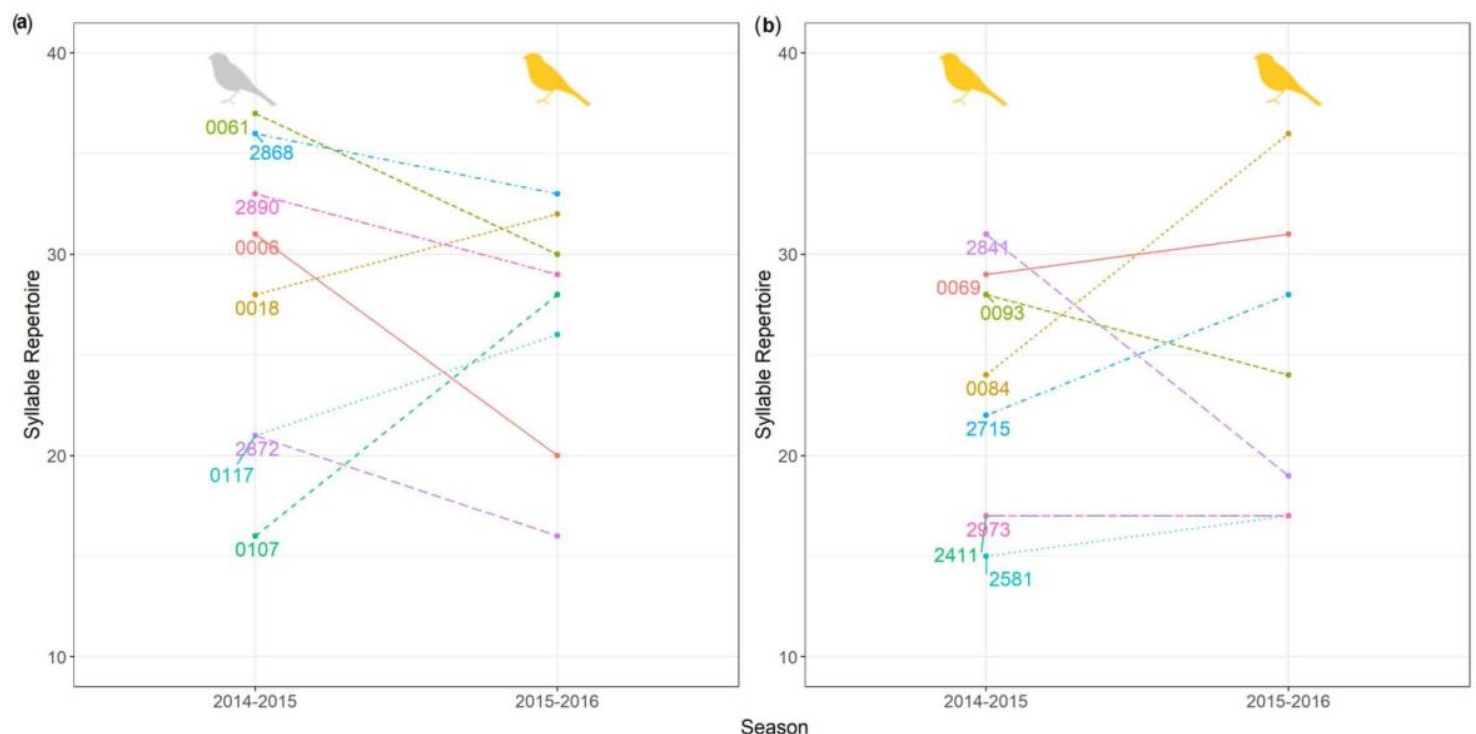
Figure 2. Scatterplots of repertoire similarity versus distance between nest-boxes (m) for saffron finches males breeding from Chascomús. Buenos Aires. Argentina, separated by age classes (second-year, after second-year) and seasons: a) 2014-2015, 91 pairwise comparisons; b) 2015-2016, 28 pairwise comparisons; c) 2014-2015, 168 pairwise comparisons; d) 2015-2016, 168 pairwise comparisons; e) 2014-2015, 66 pairwise comparisons; and f) 2015-2016, 210 pairwise comparisons.
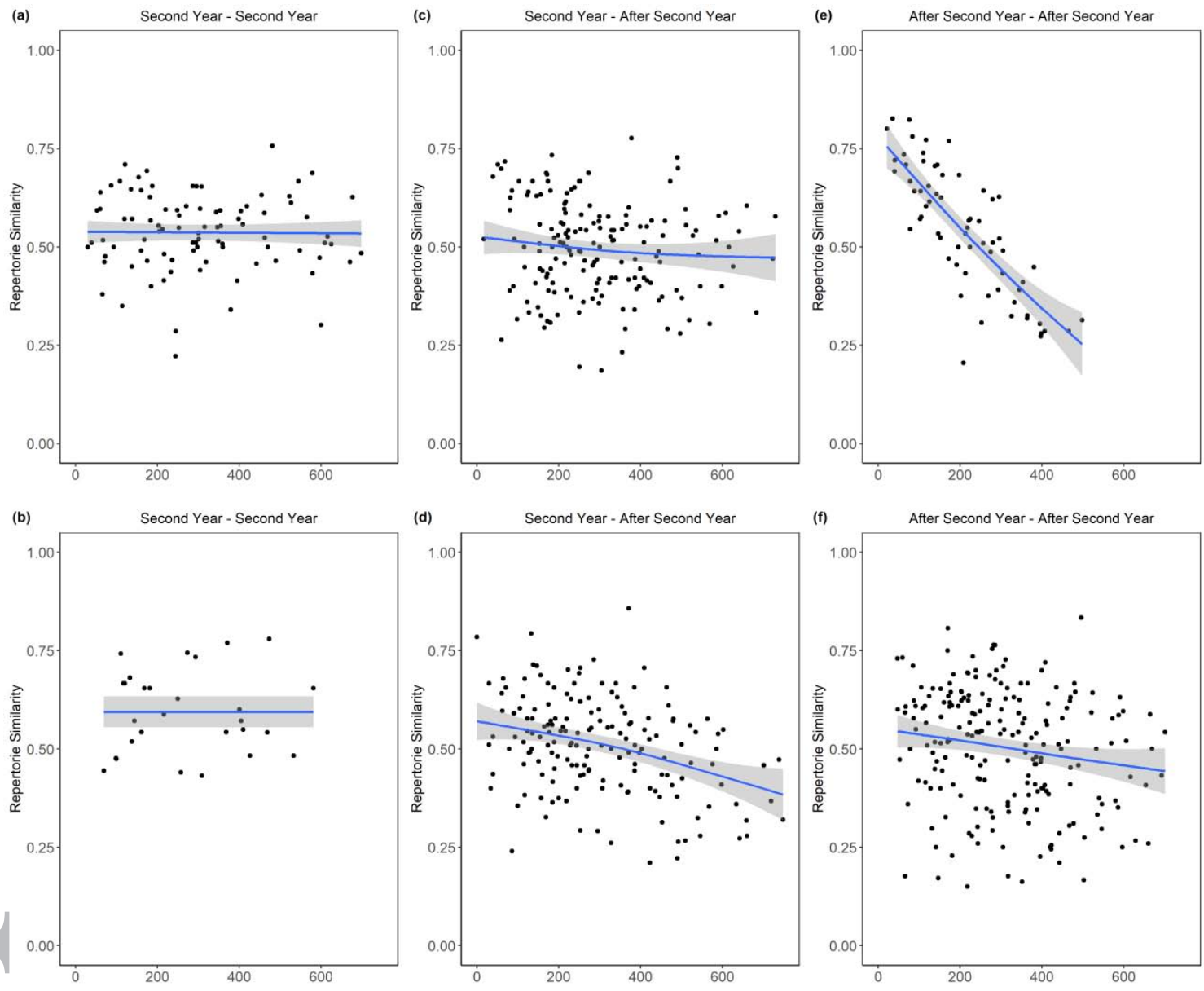
TAB $\perp \perp \ldots \ldots$

Table 1 ecults $c$ cross-sectional analysis of song variables recorded in saffron finch males of second-year, $n=22$, and after-second year, $n=7$, breeding in Chascomús, Buenos Aires, Argentina. Values of variables are reported as means \pm Standard Errors. Effect size refers to Cohen's d.

\begin{tabular}{lrrrrr}
\hline \multicolumn{1}{l}{ Variable } & \multicolumn{1}{c}{ Second-year } & After-second year & Statistic $($ d.f.:37) & Effect size & 95\% CI effect size \\
\hline Maxir. m Fre lency & $9636.70 \pm 113.25$ & $9399.50 \pm 136.63$ & $1.35^{\mathrm{a}}$ & 0.43 & $-0.24-1.14$ \\
Minimum Frequ. y & $3342.89 \pm 72.42$ & $3265.23 \pm 112.09$ & $0.60^{\mathrm{a}}$ & 0.19 & $-0.44-1$ \\
Frequency Bandwidth & $6293.84 \pm 165.50$ & $6136.97 \pm 200.85$ & $0.62^{\mathrm{a}}$ & 0.20 & $-0.47-0.85$ \\
Peak & $6376.80 \pm 68.30$ & $6134.74 \pm 85.20$ & $2.24^{\mathrm{a}}$ & 0.72 & $0.11-1.39$ \\
Song Len th & $1.67 \pm 0.12$ & $2.01 \pm 0.26$ & $138^{\mathrm{b}}$ & 0.22 & $0.01-0.51$ \\
Syllable Rate & $4.19 \pm 0.09$ & $3.93 \pm 0.125$ & $1.68^{\mathrm{a}}$ & 0.54 & $-0.11-1.28$ \\
Syllable I ura on & $0.123 \pm 0.003$ & $0.128 \pm 0.003$ & $126^{\mathrm{b}}$ & 0.28 & $0.03-0.56$ \\
Song Vers & $0.79 \pm 0.02$ & $0.83 \pm 0.02$ & $-1.57^{\mathrm{a}}$ & -0.51 & $-1.37-0.17$ \\
Syllable I epertoir Size & $28.09 \pm 1.30$ & $23.44 \pm 1.28$ & $2.52^{\mathrm{a}}$ & 0.70 & $0.05-1.52$ \\
\hline
\end{tabular}

${ }^{\text {a Comparı } o n s ~ w e r e ~ c a r r i e d ~ o u t ~ u s i n g ~ t w o-s a m p l e ~ S t u d e n t ' s ~} t$-tests.

${ }^{\mathrm{b}}$ Compari an e carried out using the Wilcoxon Rank Sum test. 
Table 2. Results of longitudinal comparisons of song variables of saffron finch males recorded as second-year (SY), and in the subseq as after-second year (ASY), $n=8$, breeding at a nest-box system located in Chascomús, Buenos Aires, Argentina. Values of ariables are reported as means \pm Standard Errors. Comparisons were carried out using paired samples Student's $t$-tests.

Effect size refers to Hedges' g.

\begin{tabular}{|c|c|c|c|c|c|}
\hline Variab' & SY males & ASY males & Statistic(d.f.:7) & Effect size & $95 \%$ CI effect size \\
\hline Maximum iency & $9612.91 \pm 158.67$ & $9636.28 \pm 176.65$ & -0.33 & -0.10 & $-0.92-0.54$ \\
\hline Minimum Frequency & $3346.34 \pm 86.84$ & $3539.97 \pm 186.61$ & -1.10 & -0.35 & $-1.11-0.33$ \\
\hline Frequency Bandwidth & $6266.57 \pm 220.42$ & $6096.30 \pm 215.71$ & 0.86 & 0.27 & $-0.51-0.92$ \\
\hline Peak rreq -ncy & $6310.54 \pm 99.0$ & $6543.21 \pm 123.74$ & -1.68 & -0.53 & $-2.01-0.04$ \\
\hline Song Len. & $1.65 \pm 0.13$ & $1.61 \pm 0.17$ & 0.24 & 0.08 & $-0.64-0.98$ \\
\hline Syllable R & $4.23 \pm 0.10$ & $4.40 \pm 0.08$ & -1.04 & -0.33 & $-0.82-0.44$ \\
\hline Syllable I ura on & $0.13 \pm 0.002$ & $0.12 \pm 0.004$ & 2.70 & 0.85 & $0.38-1.92$ \\
\hline Song Versat.., ndex & $0.74 \pm 0.02$ & $0.80 \pm 0.02$ & -2.47 & -0.78 & $-1.73--0.33$ \\
\hline Syllable I epertoir Size & $27.9 \pm 2.74$ & $26.75 \pm 2.09$ & 0.32 & 0.13 & $-0.48-1.55$ \\
\hline
\end{tabular}


Tablc 3. 1....... longitudinal comparisons of song variables of saffron finch males recorded as ASY and the same males recorded in the follow no ceas $n(A S Y+1), n=8$, breeding at a nest-box system located in Chascomús, Buenos Aires, Argentina. Values of variables re reported as means \pm Standard Errors. Effect size refers to Hedges’ g.

\begin{tabular}{|c|c|c|c|c|c|}
\hline Variable & ASYmales & ASY+1males & Statistic (d.f.: 7) & Effect size & $95 \%$ CI effect size \\
\hline Maximum ${ }^{-}-$lency & $9170.77 \pm 149.39$ & $8964.97 \pm 172.60$ & $1.79^{\mathrm{a}}$ & 0.56 & $0.02-1.81$ \\
\hline Minimur. $\sigma_{\text {moc }}$ ency & $3142.57 \pm 133.31$ & $3076.09 \pm 129.10$ & $0.62^{\mathrm{a}}$ & 0.19 & $-0.42-1.66$ \\
\hline Frequency Bandwidth & $6028.19 \pm 186.17$ & $5888.82 \pm 219.65$ & $0.67^{\mathrm{a}}$ & 0.21 & $-0.42-1.07$ \\
\hline Peak Frequency & $6071.36 \pm 141.52$ & $6221.80 \pm 99.26$ & $-1.61^{\mathrm{a}}$ & -0.51 & $-1.26-0.08$ \\
\hline Song $\mathrm{L}$ & $2.27 \pm 0.55$ & $2.03 \pm 0.22$ & $12^{\mathrm{b}}$ & 0.30 & $0-0.9$ \\
\hline Syllable 1 & $4.04 \pm 0.24$ & $4.20 \pm 0.19$ & $-0.75^{\mathrm{a}}$ & -0.24 & $-1.05-0.47$ \\
\hline Syllable D & $0.13 \pm 0.004$ & $0.12 \pm 0.003$ & $2.63^{\mathrm{a}}$ & 0.83 & $0.43-2.12$ \\
\hline Song Ver atil y In ex & $0.80 \pm 0.04$ & $0.83 \pm 0.02$ & $-0.90^{\mathrm{a}}$ & -0.28 & $-1.08-0.36$ \\
\hline Syllable R $\iota_{\Gamma} \quad$ e Size & $22.9 \pm 2.17$ & $23.62 \pm 2.60$ & -0.22 & -0.10 & $-0.98-0.52$ \\
\hline
\end{tabular}

${ }^{\mathrm{a}}$ Compari ons wer carried out using paired samples Student's $t$-tests.

${ }^{\mathrm{b}}$ Comprn 